\title{
Annual variation in temperature selection by Atlantic cod Gadus morhua in the southern Gulf of St. Lawrence, Canada, and its relation to population size
}

\author{
D. P. Swain ${ }^{1}$, D. L. Kramer ${ }^{2}$ \\ ${ }^{1}$ Department of Fisheries and Oceans, Gulf Fisheries Centre, PO Box 5030, Moncton, New Brunswick, Canada E1C 9B6 \\ ${ }^{2}$ Department of Biology, McGill University, 1205 Docteur Penfield Avenue, Montreal, Quebec, Canada H3A 1B1
}

\begin{abstract}
Using data from bottom trawl surveys conducted each September in the southern Gulf of St. Lawrence, Canada, we examined variation in the temperature distribution of Atlantic cod Gadus morhua from 1971 to 1991 . Distribution and temperature selection were described using the cumulative distribution functions of temperature and of catch of each age class in relation to temperature. Temperature distribution varied widely among years. For example, the median temperature occupied by Age 5 cod ranged from 0.3 to $7.5^{\circ} \mathrm{C}$, and the 97.5 th percentile of occupied temperatures ranged from 4.6 to $16.6^{\circ} \mathrm{C}$. Median occupied temperature decreased as age increased. Temperature selection was highly variable in both extent and direction, varying from cases of no selection to statistically significant positive or negative selection, depending on year and age class. Cod tended to select warm temperatures relative to those available in 1972 to 1976,1978 and 1991 and relatively cool temperatures in 1980 to 1990 . We used multiple regression to test for an effect of cod abundance on temperature distribution and selection, controlling for variation in available temperatures. When abundance was high, cod tended to occupy colder water, both in absolute terms (the 97.5 th, 50.0th and 2.5th percentiles of cod temperature distribution) and in relative terms (the measure of temperature selection). The 97.5th and 2.5th percentiles of occupied temperature increased with increasing available temperatures; conversely, temperature selection was inversely related to available temperature. These patterns provide the first field support for the hypothesis that a density-dependent decrease in food availability should result in increased preference for habitats with lower density-independent costs and provide a possible explanation for density-dependent shifts in spatial and bathymetric patterns in this population
\end{abstract}

KEY WORDS: Atlantic cod - Density-dependent - Distribution · Gadus morhua - Habitat selection . Temperature

\section{INTRODUCTION}

Determinants of habitat quality may be density dependent (e.g. food resources, whose benefit per individual declines with an increase in the number of individuals) or density independent (e.g. temperature, whose cost or benefit does not depend on the number of individuals in a habitat). If animals can actively choose among habitats and their choice is based on density-dependent resources, then distribution among habitats is expected to depend on population size (Fretwell \& Lucas 1970). At low population sizes, individuals should occupy only the habitats with the high- est resource levels. As population size increases, the suitability of these habitats will decline due to competition and the population should expand into habitats with lower resource levels. Thus, if habitat quality changes in a regular way with geographical location, population range should expand as abundance increases (MacCall 1990). A positive correlation between population size and range has been demonstrated for several populations of marine fishes (e.g. Winters \& Wheeler 1985, MacCall 1990, Rose \& Leggett 1991), including Atlantic cod Gadus morhua in the southern Gulf of St. Lawrence, Canada (Swain \& Wade 1993, Swain \& Sinclair 1994). If habitat selection 
is based solely on density-dependent resources, then densities are expected to remain higher in the habitats with higher levels of these resources regardless of population size. However, instead of expanding and contracting around a single 'preferred' region, the region of greatest cod density in the southern Gulf shifted with changes in the size of the cod stock (Swain \& Wade 1993). Swain \& Wade (1993) proposed that this shift could have been the result of an interaction between density-dependent benefits associated with food resources and density-independent costs associated with temperature.

Fish on unlimited rations grow most quickly at temperatures near the upper limit of their tolerated range (Brett 1979). Without food, they lose mass more slowly as temperature decreases. On limited rations, the temperature yielding the highest growth rate decreases as ration size decreases (Brett et al. 1969, Elliott 1975, Woiwode \& Adelman 1991). Therefore, if fish select the habitat which maximizes their growth rate, preferred temperatures should decrease as food supply decreases (Elliott 1979, Crowder \& Magnuson 1983). If food supply is density dependent, the proportion of the population occupying habitats of lower temperature should increase with population size. Thus, if habitat selection is based on an interaction between densitydependent food resources and density-independent thermal regime, then the highest fish density may occur in different habitats at different population sizes.
Swain \& Wade (1993) suggested that cod distribution in the southern Gulf may shift from high-resource (shallow), high-temperature habitats at low population abundance to low-resource (deeper), low-temperature habitats at high abundance. Density-dependent changes in the bathymetric pattern of southern Gulf cod are consistent with this suggestion (Swain 1993a).

Previous studies suggest that temperature is an important environmental variable for cod. Rose \& Leggett (1988) reported that the 'modal' temperature range (defined as the the temperature range at which free-ranging fish are most frequently located) was 0 to $5^{\circ} \mathrm{C}$ in summer at Brador Bay in the northern Gulf of St. Lawrence and that fewer than $5 \%$ of cod occupied temperatures outside the range -0.5 to $8.5^{\circ} \mathrm{C}$. These temperature ranges are consistent with the results of most other field studies (Jean 1964, Scott 1982, Nakken \& Raknes 1987, Smith et al. 1991, Sinclair 1992), although cod have been reported to frequent considerably higher temperatures in some populations (Bigelow \& Schroeder 1953, Scott 1982, Murawski \& Finn 1988). For example, the mean temperature occupied by cod was $7.8^{\circ} \mathrm{C}$ in summer in the Bay of Fundy, Canada, (Scott 1982) and $9.3^{\circ} \mathrm{C}$ in autumn on Georges Bank (Murawski \& Finn 1988). Temperature preferences of cod appear to be age dependent. The temperatures occupied by cod decreased from Age 1 to Age 5 in the southern Gulf of St. Lawrence in September (Tremblay \& Sinclair 1985) and on the Scotian Shelf in

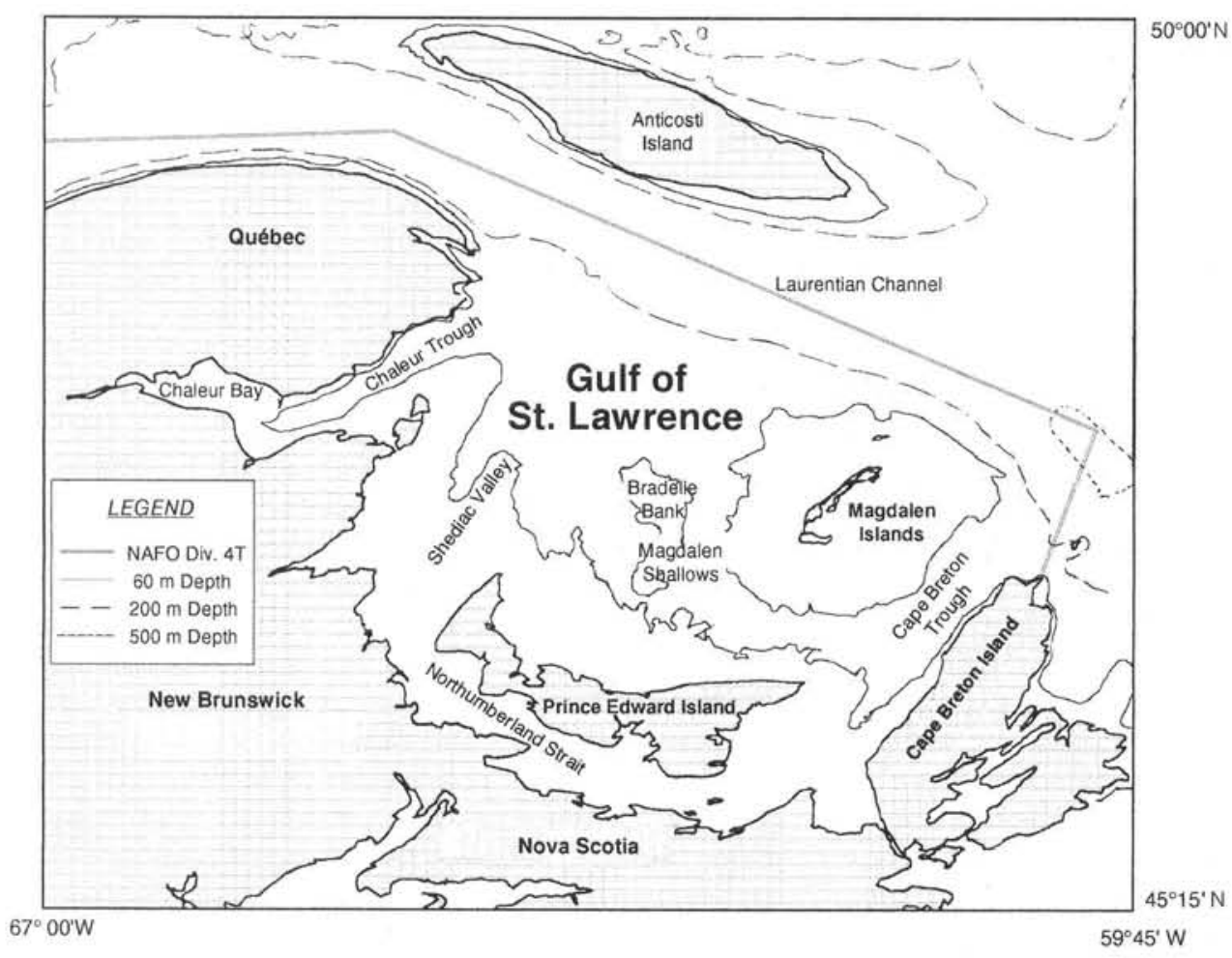

Fig. 1. Bathymetric map of the southern Gulf of St. Lawrence, Canada, showing North Atlantic Fisheries Organization division $4 \mathrm{~T}$ 
summer (Sinclair 1992) but increased from Age 1 to Age 7 in the Barents Sea in February (Nakken \& Raknes 1987).

In the present study, we examine annual variation in the temperatures occupied by cod in the southern Gulf of St. Lawrence over a $21 \mathrm{yr}$ period. We examine the degree of temperature selection by each age class of cod in each year by comparing the temperatures occupied to those available. Finally, we test effects of annual variation in thermal regime and population size on the temperatures occupied (median and upper and lower limits) and on the extent and direction of temperature selection by cod. These analyses test the hypothesis that selection of a density-independent resource can explain density-dependent changes in population distribution (Swain 1993a, Swain \& Wade 1993).

\section{MATERIAL AND METHODS}

Study area and population. The southern Gulf of St. Lawrence consists of a shallow shelf with depths mostly less than $75 \mathrm{~m}$, bordered on the north by the Laurentian Channel, with a maximum depth of $535 \mathrm{~m}$ (Fig. 1). Three water layers are present in summer and autumn: a warm surface layer, a cold $\left(-1\right.$ to $\left.2^{\circ} \mathrm{C}\right)$ intermediate layer, and a warm $\left(4\right.$ to $\left.6^{\circ} \mathrm{C}\right)$ deep layer (Koutitonsky \& Bugden 1991). The cold intermediate layer covers the bottom over much of the central area of the southern Gulf, with bottom temperatures increasing shoreward as depth decreases and towards the Laurentian Channel as depth increases (Fig. 2). Further details of September bottom temperatures in the southern Gulf are given by Swain (1993a, b). In winter, 2 water layers are present: a surface mixed layer (extending down to about $125 \mathrm{~m}$ ) with temperatures near the freezing point $\left(-1.5^{\circ} \mathrm{C}\right)$ and the warm deep layer along the edge of the Laurentian Channel.

Adult cod migrate between summer spawning and feeding grounds in the southern Gulf and overwintering grounds in the deeper, warmer water of the Sidney Bight area east of Cape Breton Island (Martin \& Jean 1964, Jean 1964). Cod migrate into the southern Gulf between late April and early June, spawn and then disperse to feeding grounds. Migration out of the southern Gulf occurs between late October and early December. This high level of mobility suggests that habitat selection can occur over a wide spatial scale in this population. Abundance of the southern Gulf cod stock has varied 4-fold between 1971 and 1991 (G. A.

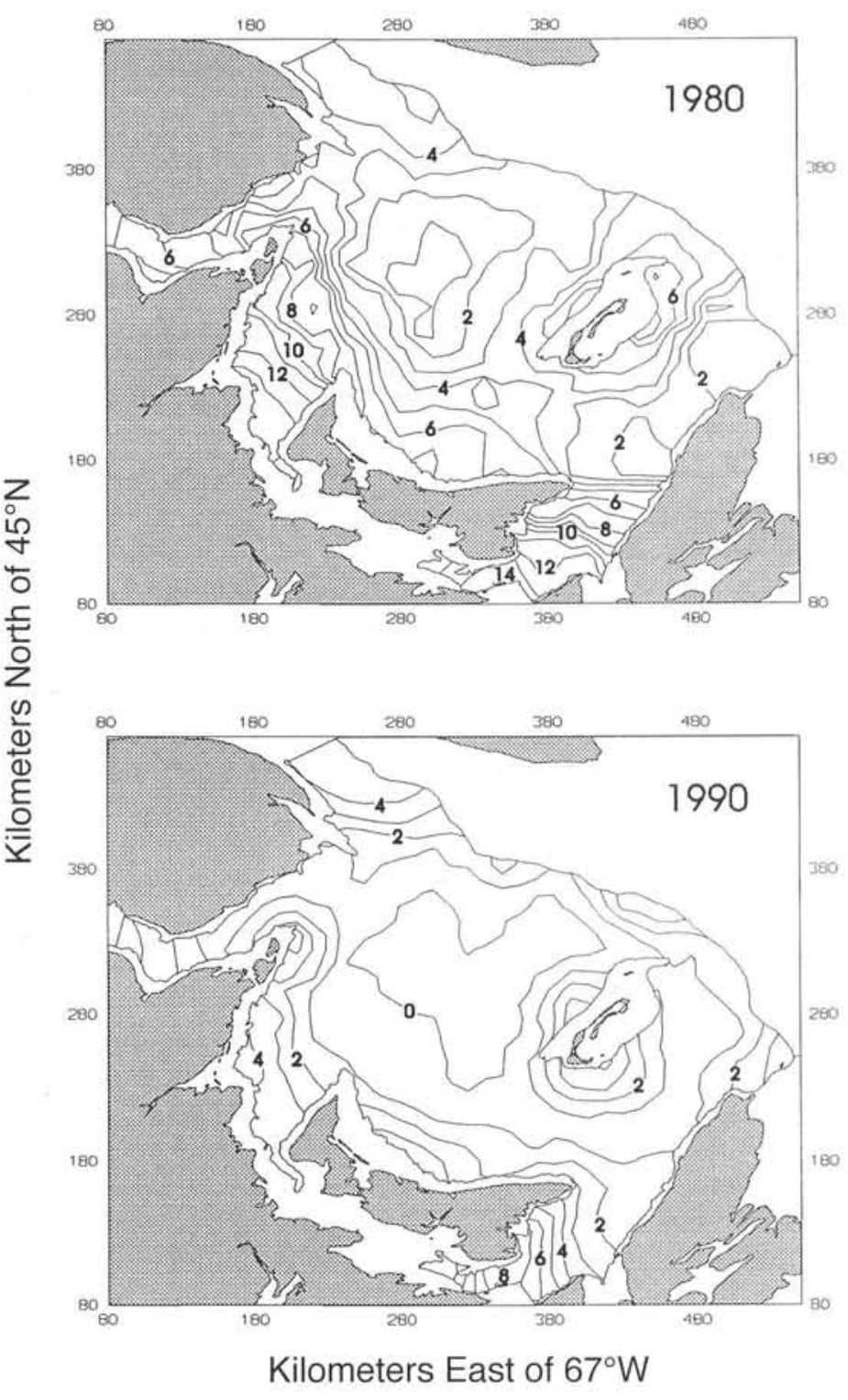

Fig. 2. September bottom temperatures $\left({ }^{\circ} \mathrm{C}\right)$ in the southern Gulf of St. Lawrence in 1980, an exceptionally warm year, and 1990, a cold year. Interpolation for contours was by ordinary kriging

Chouinard et al. unpubl.). Abundance was lowest in the mid 1970s and highest in the mid 1980s (Fig. 3). The estimated mid-year population size of cod Age 3 and older was less than 175 million between 1972 and 1976 and in 1991, and was greater than 300 million between 1978 and 1987. Growth rate has also varied widely between 1971 and 1991, declining from the 1970 s to the 1980s (Hanson \& Chouinard 1992a).

Temperature distribution. We estimated the distribution of temperature and of cod in relation to temperature from bottom trawl surveys conducted in the southern Gulf each September since 1971. (Cod are believed to be most widely dispersed throughout the southern Gulf 


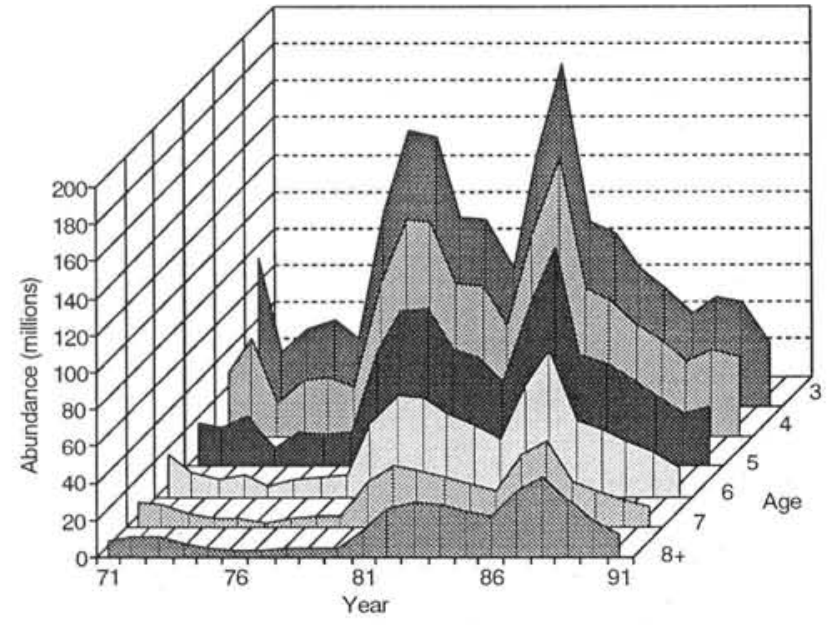

Fig. 3. Gadus morhua. Estimated mid-year abundance of cod in the southern Gulf of St. Lawrence, 1971 to 1991 (data from G.A. Chouinard et al.)

in September; Clay 1991.) Surveys used a stratified random design, with stratification based on depth and geographic region. Survey procedures are described by Hurlbut \& Clay (1990) and summarized by Swain \& Wade (1993). Cod catch-at-age was estimated for each trawl tow as described by Swain \& Wade (1993). Catches were adjusted to a standard tow length of 1.75 nautical miles. Near-bottom temperature was measured after each tow using reversing thermometers and mechanical bathythermographs (MBTs) in 1971 to 1983, MBTs in 1984 to 1988 , an electronic bathythermograph (Femto model 8720) in 1989 and 1990, and a Seabird SBE-19 probe in 1991. The MBTs used in 1984 to 1988 permitted temperature measurements only to a depth of $145 \mathrm{~m}$. Tows at depths greater than $155 \mathrm{~m}$ were omitted from analyses in all years so that results would be comparable among years. Six strata had a high proportion of tows at depths greater than $155 \mathrm{~m}$ (50 to $100 \%$ in some years) and were omitted from analyses (strata 15, 25, 26, $37,38,39 ; 14 \%$ of the survey area; see Fig. 2 in Swain \& Wade 1993). Cod tended to be rare in these deep strata; estimated cod biomass in these strata was on average less than $6 \%$ of the survey total in 1971 to 1991 . Sample sizes used in these analyses ranged from 41 (1977) to 156 (1991) tows $\mathrm{yr}^{-1}$.

We examined relationships between cod density (fish per standard tow) and temperature using cumulative distribution functions (CDFs) following Perry \& Smith (1994). The CDF (in \%) for temperature was calculated for each year from 1971 to 1991 as follows:

$$
f(t)=100 \frac{\sum_{h=1}^{L} \sum_{i=1}^{n_{h}} \frac{A_{h}}{n_{h}} I}{\sum_{h=1}^{L} \sum_{i=1}^{n_{h}} \frac{A_{h}}{n_{h}}} \quad \text { where } I=\left\{\begin{array}{l}
1, \text { if } x_{h i} \leq t \\
0, \text { otherwise }
\end{array}\right.
$$

where $t$ is a level of temperature, $A_{h}$ is the area of stratum $h, n_{h}$ is the number of tows in stratum $h, x_{h i}$ is the bottom temperature at the end of tow $i$ in stratum $h$, and $L$ is the number of strata. The CDF for cod catch in relation to temperature was calculated similarly:

$$
g(t)=100 \frac{\sum_{h=1}^{L} \sum_{i=1}^{n_{h}} \frac{A_{h}}{n_{h}} y_{h i} I}{\sum_{h=1}^{L} \sum_{i=1}^{n_{h}} \frac{A_{h}}{n_{h}} y_{h i}} \quad \text { where } I=\left\{\begin{array}{l}
1, \text { if } x_{h i} \leq t \\
0, \text { otherwise }
\end{array}\right.
$$

where $y_{h i}$ is the number of cod caught in tow $i$ in stratum $h$. We calculated the cod CDF separately for each age from 3 to 7 and for fish Age 8 and older (hereafter $\left.8^{+}\right)$.

We examined annual variation in the median temperature occupied by cod and in the temperature limits of cod distribution. Following Rose \& Leggett (1988, 1989), we defined these limits as the range of temperatures within which $95 \%$ of cod occurred, i.e. the 2.5 th and 97.5th percentiles of the CDFs of cod catch in relation to temperature. Percentiles were calculated by interpolation from CDFs calculated at $0.1^{\circ} \mathrm{C}$ intervals from -2.0 to $20.0^{\circ} \mathrm{C}$. We tested effects of year and age on the temperatures occupied by cod using a 2-way fixed effects ANOVA model without interaction (degrees of freedom were insufficient to include interaction terms). To test for longer term variation, we divided the 21 yr time series into 2 periods (1971 to 1981 and 1982 to 1991). We analyzed these data using ANOVA with age, period and their interaction as fixed effects and year nested within period as a random effect. Tests of the effect of period used the Type III mean squared for the effect of year nested within period as the error term $(\mathrm{df}=1,19)$.

To examine annual variation in temperature selection by cod, we compared CDFs of temperature and of cod catch in relation to temperature. We calculated

$$
S=\sum_{t=-1}^{20}[f(t)-g(t)]
$$

for each year and age group. $S$ compares the average available temperature to the average temperature selected by cod. Positive values for $S$ indicate selection of relatively warm temperatures in relation to those available. Following Perry \& Smith (1994), we used a Kolmogorov-Smirnov type of statistic to test the significance of temperature selection. The test statistic $D$ was the maximum absolute vertical distance between $f(t)$ and $g(t)$, with the 2 functions compared at $0.5^{\circ} \mathrm{C}$ intervals from -1.0 to $20.0^{\circ} \mathrm{C}$, inclusive. Significance was assessed using randomization tests (Edgington 1987). For each age group and year, we first calculated $D$ for the observed data. Then we randomly redistributed cod catches among temperatures 2999 times, cal- 
culating $D$ for each random permutation of the data. We determined $N$, the number of random permutations with $D$ equal to or greater than that of the observed data, and calculated $P=(N+1) / 3000$. $P$ is the probability of observing a value of $D$ equal to or greater than that of the observed data under the null hypothesis that cod are distributed randomly in relation to temperature.

We tested the density dependence of cod temperature distribution using analysis of covariance with age as a class variable and measures of abundance and available temperature as covariates. We tested 3 measures of temperature distribution (the median and upper and lower limits of cod temperature distribution) as well as the measure of temperature selection $S$. All 4 measures could be influenced by temperature availability. On the one hand, if temperature preferences are weak in relation to other habitat determinants, a positive correlation is expected between occupied and available temperatures. On the other hand, if temperature preferences are strong in relation to other habitat determinants, a negative correlation is expected between $S$ and available temperature. To control for variation in available temperature, we included median available temperature as a covariate in analyses of $S$ and of median occupied temperature, and the upper or lower limit of available temperature as a covariate in analyses of the upper or lower temperature limit of cod distribution. Because we predicted the direction of association between cod distribution and available temperature, tests of the significance of these temperature covariates are 1-tailed. We used mid-year abundance estimates calculated from data from G. A. Chouinard et al. (unpubl.). Because competition should be strongest within age classes but may also occur between age classes, we considered 3 measures of abundance: (1) $N_{i}$, the abundance of age group $i$; (2) the abundance of age group $i$ and adjacent age groups; and (3) the total abundance of cod Age 3 and older. Results were similar and led to the same conclusions about the density dependence of cod temperature distribution for all 3 measures of abundance. Only the results using $N_{i}$ are reported here. Because $N_{i}$ varied substantially among age classes (e.g. 29 to 185 million for Age 3 versus 3 to 43 million for Age $8^{+}$), we standardized $N_{i}$ to a mean of 0 and a standard deviation of 1 within age classes. (Results were similar and conclusions the same using the raw $N_{i}$.) Because we predicted a negative association between temperature use and abundance, tests of the effect of abundance are 1tailed. For each analysis, we first fitted a separateslopes model to test for homogeneity of covariate slopes among age classes. When slopes were not significantly ( $p>0.05$ ) heterogeneous among age classes, a second common-slope model was used. Analyses used the GLM procedure of SAS (SAS Institute 1990).

\section{RESULTS}

\section{Annual and age-dependent variation in cod temperature distribution}

Variation among age classes (Table 1) was significant for the lower limit of cod temperature distribution $\left(F_{5,100}=2.87, \mathrm{p}=0.018\right)$ and for the median temperature occupied by $\operatorname{cod}\left(F_{5,100}=7.79, \mathrm{p}<0.0001\right)$, but not for the upper limit of distribution $\left(F_{5,100}=0.18, \mathrm{p}=\right.$

Table 1. Gadus morhua. Available temperatures and temperatures occupied by cod Ages 3 to $8^{+}$in the southern Gulf of St. Lawrence in September 1971 to 1991. Percentiles are of the annual cumulative distribution functions of temperature (available) and of cod with respect to temperature (occupied)

\begin{tabular}{|c|c|c|c|c|c|c|c|c|}
\hline \multirow{2}{*}{ Percentile } & \multirow{2}{*}{ Statistic } & \multirow{2}{*}{$\begin{array}{l}\text { Available } \\
\text { temp. }\left({ }^{\circ} \mathrm{C}\right)\end{array}$} & \multicolumn{6}{|c|}{ Occupied temperature $\left({ }^{\circ} \mathrm{C}\right)$} \\
\hline & & & 3 & 4 & 5 & 6 & 7 & $8^{+}$ \\
\hline \multirow[t]{4}{*}{2.5} & Mean & -0.41 & -0.17 & -0.28 & -0.29 & -0.29 & -0.28 & -0.25 \\
\hline & SE & 0.09 & 0.08 & 0.09 & 0.09 & 0.09 & 0.08 & 0.07 \\
\hline & Min. & -1.27 & -0.99 & -1.26 & -1.25 & -1.22 & -1.10 & -0.99 \\
\hline & Max. & 0.25 & 0.33 & 0.30 & 0.30 & 0.26 & 0.27 & 0.30 \\
\hline \multirow[t]{4}{*}{50.0} & Mean & 0.85 & 2.71 & 1.84 & 1.66 & 1.58 & 1.61 & 1.57 \\
\hline & SE & 0.15 & 0.54 & 0.42 & 0.43 & 0.40 & 0.40 & 0.31 \\
\hline & Min. & -0.23 & 0.36 & 0.25 & 0.30 & 0.32 & 0.29 & 0.34 \\
\hline & Max. & 3.19 & 11.02 & 7.56 & 7.50 & 7.31 & 7.30 & 6.31 \\
\hline \multirow[t]{4}{*}{97.5} & Mean & 13.09 & 9.66 & 9.56 & 9.81 & 9.79 & 9.67 & 9.72 \\
\hline & SE & 0.45 & 0.89 & 0.82 & 0.83 & 0.80 & 0.81 & 0.77 \\
\hline & Min. & 8.35 & 3.12 & 4.61 & 4.63 & 4.64 & 3.80 & 3.74 \\
\hline & Max. & 16.61 & 16.09 & 16.61 & 16.59 & 16.09 & 16.04 & 15.32 \\
\hline
\end{tabular}




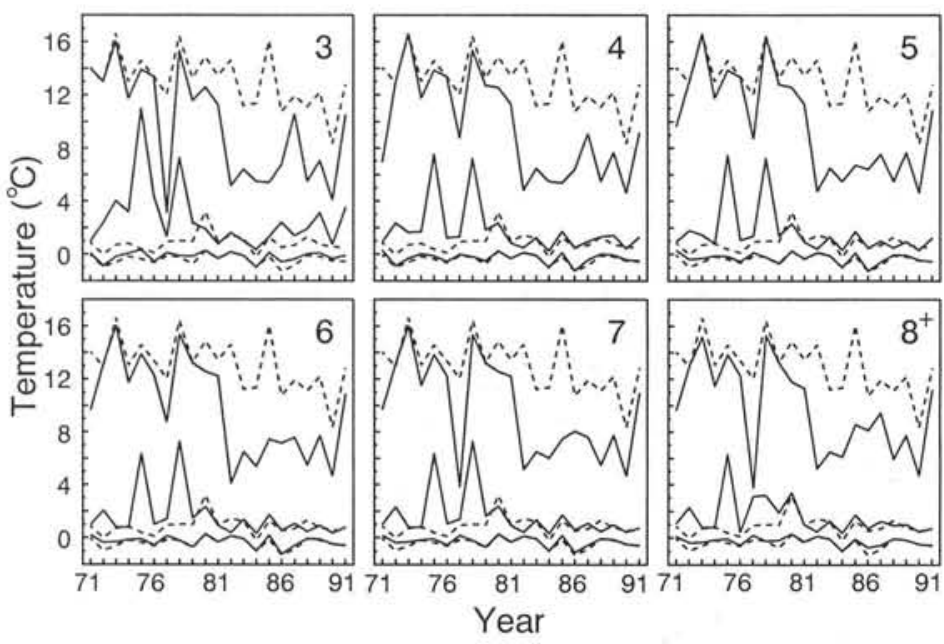

Fig. 4, Gadus morhua. The 2.5th, 50.0th and 97.5th percentiles of the distributions of temperature (dashed line) and cod catch in relation to temperature (solid line) in September in the southern Gulf of St. Lawrence for the years 1971 to 1991 . Age classes $3,4,5,6,7$, and $8^{+}$are illustrated in separate panels

the upper limit of occupied temperatures (Fig. 4). Median occupied temperature varied from 0.9 to $1.3^{\circ} \mathrm{C}$ (depending on age) below median available temperature to 5.9 (Age $8^{+}$) to $10.6^{\circ} \mathrm{C}$ (Age 3 ) above that temperature.

Annual variation in the temperature distribution of cod showed a clear temporal pattern (Fig. 4). Cod tended to occupy warmer water early (1971 to 1981) in the time series (Table 2). This pattern was most striking for the upper limit $\left(F_{1,19}=29.887, \mathrm{p}<0.0001\right)$, but was also significant for the median occupied temperature $\left(F_{1,19}=4.7331, \mathrm{p}=0.042\right)$. The lower limit did not differ significantly between the 2 halves of the time series $\left(F_{1,19}\right.$ $=1.087, \mathrm{p}=0.31$ ). Available temperatures did not show comparable temporal trends in either the upper limit or the median (Fig. 4 , Table 2).

\section{Temperature selection}

0.97). The median occupied temperature decreased from Age 3 to Age 6 (Table 1). The lower limit to distribution was also warmer for Age $3 \operatorname{cod}\left(-0.17^{\circ} \mathrm{C}\right)$ than for older $\operatorname{cod}\left(-0.25\right.$ to $\left.-0.29^{\circ} \mathrm{C}\right)$.

Variation among years was highly significant $(\mathrm{p}<$ 0.0001 ) for all 3 measures of cod temperature distribution (lower limit: $F=48.97$; median: $F=37.55$; upper limit: $F=81.89$; df $=20,100$ ). The lower limit showed relatively small variation among years (Table 1 ; range 1.3 to $1.6^{\circ} \mathrm{C}$ depending on age) and was always close $\left(0.01\right.$ to $\left.0.7^{\circ} \mathrm{C}\right)$ to the lower limit of available temperature (Fig. 4). In contrast, the upper limit showed striking variation among years (Table 1 ; range 11.5 to $13.0^{\circ} \mathrm{C}$ ). Upper limits were within $0.1^{\circ} \mathrm{C}$ of the upper limit of available temperature in some years, but were 9 to $11^{\circ} \mathrm{C}$ below that available in other years (Fig. 4). Except in 1975 and 1978, the median temperature occupied by cod was much closer to the lower than to
Temperature selection by cod varied widely among years in both extent and direction. Fig. 5 shows the cumulative distribution functions of temperature and of cod with respect to temperature for selected years spanning the range of variation in selection. Randomization tests based on the maximum vertical distance between the CDFs indicated significant temperature selection $(P<0.05)$ in 3 (Age 7 ) to 6 (Ages 3 and 4 ) of the 21 years (Fig. 6$)$. A strong $(P<0.10)$ tendency toward nonrandom association between cod and temperature was present in 7 (Ages 6 to $8^{+}$) to 8 (Ages 3 to 5 ) of the 21 years. Variation in the extent of temperature selection by cod could be an artifact of variation in the extent of the survey area outside the temperature limits which cod were willing to use. To check this possibility, we recalculated the CDFs and randomization

Table 2. Gadus morhua. Average available temperature and average temperatures occupied by cod Ages 3 to $8^{+}$during 2 periods in the southern Gulf of St. Lawrence. Averages are of the indicated percentiles of the cumulative distribution functions of temperature and of cod catch in relation to temperature from annual research surveys

\begin{tabular}{|c|c|c|c|c|c|c|c|c|}
\hline \multirow[t]{2}{*}{ Percentile } & \multirow[t]{2}{*}{ Period } & \multirow{2}{*}{$\begin{array}{l}\text { Available } \\
\text { temp. }\left({ }^{\circ} \mathrm{C}\right)\end{array}$} & \multicolumn{6}{|c|}{ Occupied temperature $\left({ }^{\circ} \mathrm{C}\right)$} \\
\hline & & & 3 & 4 & 5 & 6 & 7 & $8^{+}$ \\
\hline \multirow[t]{2}{*}{2.5} & 1971-1981 & -0.36 & -0.13 & -0.22 & -0.20 & -0.20 & -0.20 & -0.15 \\
\hline & $1982-1991$ & -0.46 & -0.21 & -0.35 & -0.39 & -0.38 & -0.37 & -0.37 \\
\hline \multirow[t]{2}{*}{50.0} & $1971-1981$ & 0.90 & 3.60 & 2.63 & 2.43 & 2.30 & 2.35 & 2.20 \\
\hline & $1982-1991$ & 0.80 & 1.74 & 0.96 & 0.82 & 0.79 & 0.80 & 0.88 \\
\hline \multirow[t]{2}{*}{97.5} & $1971-1981$ & 14.05 & 12.37 & 12.38 & 12.72 & 12.62 & 12.14 & 11.88 \\
\hline & $1982-1991$ & 12.03 & 6.69 & 6.45 & 6.60 & 6.67 & 6.95 & 7.34 \\
\hline
\end{tabular}


tests omitting tows at temperatures rarely occupied by cod. We omitted temperatures below the lowest 5th percentile $\left(-0.9\right.$ to $-1.0^{\circ} \mathrm{C}$ depending on age) and above the highest 95th percentile $\left(13.5\right.$ to $\left.15.4^{\circ} \mathrm{C}\right)$ of the CDFs of cod catch in relation to temperature. This re-analysis did not result in any reduction in the number of cases of significant selection. After omission of these extreme temperatures, temperature selection was significant $(P<0.05)$ in 4 (Age 7 ) to 9 (Age 3 ) of the 21 years.

A temporal pattern is evident in the direction of temperature selection (Fig. 6). Cod tended to select warm temperatures relative to those available in 1972 to 1979 (with the exception of 1977) and in 1991 and to select relatively cool temperatures in 1980 to 1990 . Selection was most extreme for warm temperatures in 1975 and for cool temperatures in 1982 (Figs. 5 \& 6). The preference for warm water in 1975 was highly significant $(P<0.01)$ for all age classes except Age $8^{+}(P<0.05)$. Conversely, the preference for cool water in 1982 was highly significant $(P<0.01)$ for all ages except Age $4(P<0.05)$ and Age $3(P>0.10)$. Selection of relatively warm water early (1972 to 1979 )
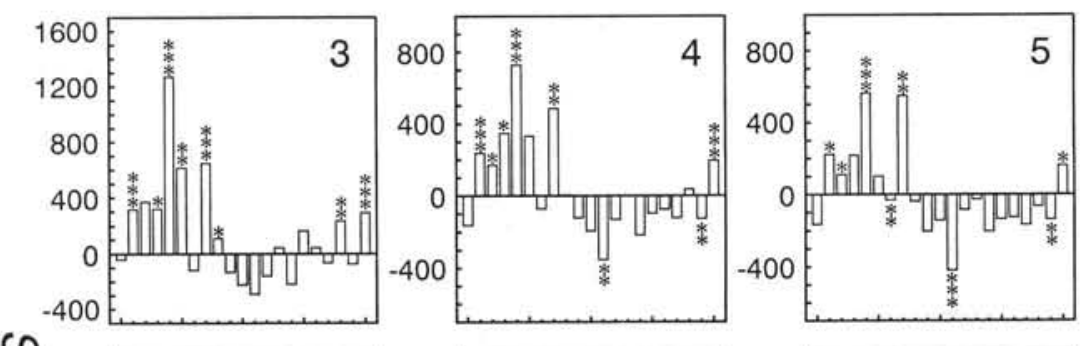

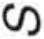
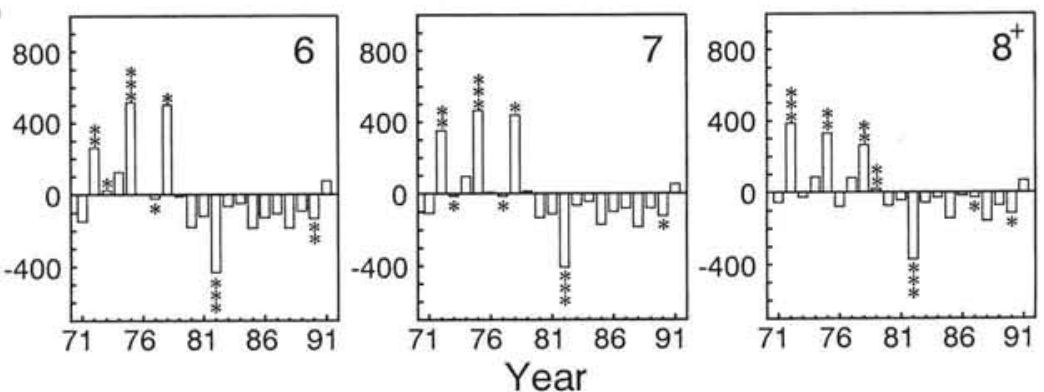

Fig. 6. Gadus morhua. Index of temperature selection (S) by cod Ages 3 to $8^{+}$in September in the southern Gulf of St. Lawrence. $S$ compares the average temperature occupied by cod with that available. Positive values indicate selection of relatively warm temperatures by cod. Asterisks give the statistical significance of temperature selection based on the randomization test described in the text $\left({ }^{\circ} P<\right.$ $0.1, \cdots P<0.05, \cdots P<0.01)$. Note difference in scale of $y$-axis of the Age 3 panel and late (1991) in the time series tended to be more statistically significant than selection of relatively cool water in the 1980 to 1990 period. Age 3 cod showed more years of positive temperature selection than other age classes (Fig. 6). Age 3 cod never showed significant negative temperature selection, while other age classes showed significant negative selection in

1 (Ages 7 to $8^{+}$) or 2 (Ages 4 to 6 ) years. In some cases (i.e. Age 5 in 1977, Age $8^{+}$in 1979), temperature selection was statistically significant but did not result in a substantial difference between the average occupied and available temperatures (Fig. 6). In other cases (e.g. Age 3 in 1973, Age 4 in 1976, Ages 6 and 7 in 1978), average occupied and available temperatures differed substantially but temperature selection was not statistically significant (Fig. 6).

\section{Effects of abundance and thermal regime}

All 4 measures of cod temperature use were significantly related to population abundance (Table 3 ). As predicted by bioenergetic arguments (see 'Introduction'), cod tended to select colder tempera- 
Table 3. Gadus morhua. Multiple regression analysis of the effects of cod abundance and thermal regime on cod temperature distribution. $S$ is an index of temperature selection. $T_{\mathrm{LO}}, T_{50}$, and $T_{\mathrm{HI}}$ are the $2.5 \mathrm{th}, 50$ th and 97.5th percentiles of the cumulative distribution function of cod catch in relation to temperature. The thermal regime covariate is the corresponding percentile of the CDF of available temperature. Median available temperature is the covariate for $S$. Probabilities are 1-tailed for the effects of abundance and thermal regime

\begin{tabular}{|lrccc|}
\hline & $S$ & $T_{\mathrm{LO}}$ & $T_{50}$ & $T_{\mathrm{HI}}$ \\
\hline Probabilities & & & & \\
Homogeneous slopes & & & & \\
$\quad$ Abundance & 0.95 & 0.97 & 0.76 & 0.87 \\
$\quad$ Thermal regime & 0.81 & 0.32 & 0.91 & 0.89 \\
Common-slope model & & & & \\
$\quad$ Age & 0.14 & 0.13 & 0.34 & 1.00 \\
$\quad$ Abundance & $<0.0001$ & 0.0006 & 0.0067 & $<0.0001$ \\
$\quad$ Thermal regime & 0.0002 & $<0.0001$ & 0.21 & $<0.0001$ \\
Slopes & & & & \\
Abundance & & & & \\
$\quad b$ & & & & \\
SE & -86.790 & -0.04897 & -0.4502 & -1.1028 \\
Thermal regime & 20.677 & 0.01461 & 0.1792 & 0.2487 \\
$\quad b$ & & & & \\
$\quad$ SE & -113.233 & 0.8504 & 0.2140 & 1.1075 \\
& 29.984 & 0.0368 & 0.2599 & 0.1219 \\
\hline
\end{tabular}

Because the area occupied by cod in the southern Gulf has expanded with increased abundance (Swain \& Sinclair 1994), it is possible that these density-dependent changes in cod temperature distribution result simply from range expansion at higher population sizes. To examine this possibility, we conducted a second analysis in which comparisons between the temperatures occupied by cod and those available were restricted to the geographic range of cod in each year. Following Swain \& Sinclair (1994), we defined the range as the area containing $95 \%$ of cod of a particular age in a particular year, and calculated CDFs of temperature and of cod catch in relation to temperature using only those tows that occurred within the range. This procedure can be described by modifications of Eqs. (1) and (2) in which both the numerator and denominator terms are multiplied by a factor $J$, where $J=1$ if $y_{h i}$ is greater than the catch rates associated with the most sparsely distributed $5 \%$ of cod of that age in that year and $J=0$ otherwise. We repeated the analysis of covariance using measures of tempera-

tures at higher levels of abundance. This inverse relationship between abundance and temperature distribution held both in absolute terms (the upper limit, median and lower limit of occupied temperatures) and relative to available temperatures $(S$, Fig. 7$)$. This relationship with abundance was stronger for the measure of temperature selection $S$ and the upper and lower temperature limits of cod distribution than for the median temperature occupied by cod (Table 3 ). The effect of abundance did not differ significantly among age classes for any of the 4 measures of cod temperature use $(\mathrm{p}=0.76$ to 0.97; Table 3).

The upper and lower limits of cod temperature distribution showed a significant positive relation to available temperatures but the median did not (Table 3). Conversely, temperature selection $S$ was negatively related to median available temperature. These effects of thermal regime on cod temperature use did not differ significantly among age classes $(\mathrm{p}=0.32$ to 0.92 , Table 3).
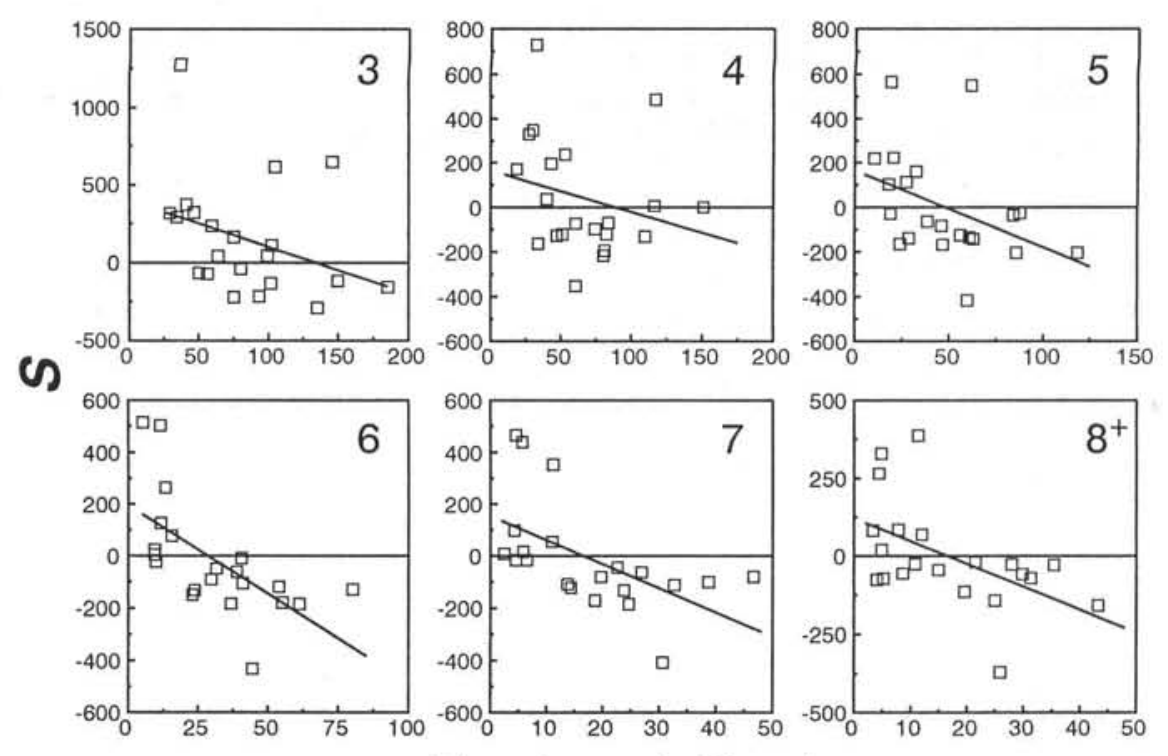

Abundance (millions)

Fig. 7. Gadus morhua. Relationships between $S$, an index of temperature selection, and abundance for cod Ages 3 to $8^{+}$. Within-age-class regression lines are shown. Slopes are significantly less than zero $(\mathrm{p}<0.05)$ for Ages 5 to $8^{+}$. Note differences in scale of $x$ - and $y$-axes 
median temperature occupied by $\operatorname{cod}(b=-0.2847$, SE $=0.1383, \mathrm{p}=0.021)$ and the upper limit of cod temperature distribution $(b=-0.5803, \mathrm{SE}=0.1601, \mathrm{p}=0.0002)$ but not for the lower limit $[b=0.0007, \mathrm{SE}=0.0141$, $\mathrm{p}(2$-tailed $)=0.96]$.

\section{DISCUSSION}

The temperatures occupied by cod in the southern Gulf of St. Lawrence in September varied widely among years. This variation was most striking for the upper temperature limit to cod distribution, which ranged from 3.1 to $16.6^{\circ} \mathrm{C}$. Depending on age class, this upper limit differed among years by 11.6 to $13.0^{\circ} \mathrm{C}$. Rose \& Leggett $(1988,1989)$ reported $8.5^{\circ} \mathrm{C}$ as the limit above which cod were rarely found in Brador Bay in the northern Gulf of St. Lawrence. In contrast, in the southern Gulf cod population, this upper limit to distribution averaged $12.4^{\circ} \mathrm{C}$ in the $1970 \mathrm{~s}$ and $6.8^{\circ} \mathrm{C}$ in the 1980 s. Since the upper limits of available temperature differed only slightly $\left(14.0\right.$ vs $\left.12.0^{\circ} \mathrm{C}\right)$ between these periods, it is not likely that this variation in the temperature distribution of cod was due simply to variation in available temperature. Laboratory estimates of the upper temperature tolerated by cod range from $16-17^{\circ} \mathrm{C}$ to $23-24^{\circ} \mathrm{C}$ depending on acclimation temperature (Jobling 1988). The upper temperature limits of cod distribution in the southern Gulf approached the lower values in this range in some years in the $1970 \mathrm{~s}$ but were well below these values in most years in the 1980s. Upper limits to thermal tolerance typically change about $1^{\circ} \mathrm{C}$ for a $3^{\circ} \mathrm{C}$ change in acclimation temperature (Fry 1971). Since the median available temperature was nearly the same in 1971 to $1981\left(0.9^{\circ} \mathrm{C}\right.$ on average) and in 1982 to $1991\left(0.8^{\circ} \mathrm{C}\right.$ on average), it is unlikely that annual variation in the upper limit to cod distribution was due simply to variation in temperature tolerance resulting from differences in acclimation.

Lower temperature limits to cod distribution varied little during the $21 \mathrm{yr}$ time series, ranging from -1.3 to $0.3^{\circ} \mathrm{C}$. These lower limits were near the lower limits of available temperature even in the 1970 s when cod tended to occupy relatively warm water, and are close to previous reports of the lower temperature limit to cod distribution $\left(-0.5^{\circ} \mathrm{C}\right.$; Rose \& Leggett 1988). Because there was little habitat below the lower temperature limits occupied by cod (Fig. 4), cod distribution in the southern Gulf in September did not appear to be strongly constrained by the lower limits to temperature selection.

Median occupied temperatures ranged from 0.3 to $11.0^{\circ} \mathrm{C}$, averaging from 1.6 (Ages 6 to $8^{+}$) to $2.7^{\circ} \mathrm{C}$ (Age 3 ) over the $21 \mathrm{yr}$ time series. Jobling (1988) estimated a final temperature preferendum of $13.5^{\circ} \mathrm{C}$ for juvenile cod and suggested that temperature preferences might be slightly lower for older cod. Clark \& Green (1991) reported seasonal variation in the final temperature preferences of juvenile cod, with preferred temperatures ranging from $-0.5^{\circ} \mathrm{C}$ in spring to 9 to $10^{\circ} \mathrm{C}$ in autumn for fish acclimated to ambient temperatures. In most years and for all ages, the median temperatures occupied by cod in September in the southern Gulf (Fig. 4) were far below Clark \& Green's autumn estimate of preferred temperature. Median or mean temperatures occupied by cod were likewise low $\left(2\right.$ to $4^{\circ} \mathrm{C}$ ) for Ages 2 to 12 on the eastern Scotian Shelf in summer (Sinclair 1992) but approached the laboratory estimates of preferred temperature in the Bay of Fundy $\left(7.8^{\circ} \mathrm{C}\right.$; Scott 1982$)$ and on Georges Bank $\left(9.3^{\circ} \mathrm{C}_{i}\right.$ Murawski \& Finn 1988). Field studies of other fish species have also reported selection of temperatures colder than laboratory-determined final preferenda (Ferguson 1958, Brett 1971, Rudstam \& Magnuson 1985). This difference has been attributed to age differences between laboratory and wild fish (Ferguson 1958 ) or to the selection of relatively cold temperatures in the wild to maximize growth rates given limited food resources (Brett 1971, Biette \& Geen 1980, Rudstam \& Magnuson 1985).

It is important to consider whether the apparent temperature selection demonstrated here could reflect selection for some correlated variable. Temperature and depth are closely correlated in the southern Gulf (e.g. Swain 1993a). Depth may also be correlated with prey abundance, with greater prey resources in shallower water (see references in Hawkins et al. 1985, Swain 1993a). Thus, apparent selection for temperature could reflect selection for depth or correlated prey resources. However, for most age/year combinations, models including both temperature and depth predict cod distribution in the southern Gulf significantly better than models containing either parameter alone [D. P. Swain unpubl.; models containing depth terms were significantly ( $\mathrm{p}<0.05$ ) improved by adding temperature terms in 83 of 126 cases; those containing temperature terms were significantly improved by adding depth terms in 107 of 126 cases]. This suggests that depth and temperature both influence the habitat preferences of cod and that temperature selection is not simply due to selection for depth or one of its other correlates such as prey abundance.

Both the absolute and the relative temperatures occupied by cod in the southern Gulf were affected by the available thermal regime. The negative relationship between temperature selection $(S)$ and thermal regime suggests a tendency to regulate temperature (i.e. to select relatively warm temperatures when conditions are cool, and vice versa). On the other hand, the positive relationships between the limits of cod tem- 
perature distribution and those of available temperature indicate that temperature was not closely regulated by cod (i.e. cod tended to occur in warmer water in warmer years). Such patterns would be expected if temperature preferences influenced habitat use but interacted with other factors in determining spatial distribution.

Population size was a significant correlate of annual variation in the temperature distribution of cod in the southern Gulf. Cod tended to occupy relatively warm water in the 1970 s when abundance was low and to occupy relatively cold water in the 1980 s when abundance was high. This result is consistent with predictions from bioenergetic studies of the interactive effects of temperature and ration size on growth in fishes. However, it is possible that some other factor differing between the 1970 s and the 1980 s could have produced a spurious correlation between cod abundance and temperature distribution. For example, prey type and abundance are likely to be important determinants of habitat quality. Changes in the diet of cod in the southern Gulf have been documented between 1955 and 1990 (Powles 1958, Kohler \& Fitzgerald 1969, Waiwood 1981, Waiwood \& Majkowski 1984, Hanson \& Chouinard 1992b), but these changes are as likely to be a consequence as a cause of changes in distribution. The changes in temperature selection reported here could result from an increase in the abundance of prey in cold water relative to warm water in the 1980 s (when cod abundance was high). However, the diet of cod is varied and strongly age- or size-dependent (see above references). Thus, changes in the abundance or distribution of a large number and variety of prey taxa would be required to explain the observed changes in distribution of cod over a range of ages. We know of no evidence for such widespread changes. Likewise, because the correlation between cod temperature distribution and abundance was significant when variation in available temperature was statistically controlled, this correlation cannot be attributed to confounding with variation in thermal regime. Thus, we are unable to suggest an alternative to density dependence to explain the changes in cod temperature distribution in the southern Gulf between the 1970s and the 1980s.

Cod abundance in the southern Gulf has declined to low levels in the 1990s. If temperature distribution and abundance are inversely related, cod distribution should shift toward warmer temperatures in the early 1990s. Results for 1991 are consistent with this expectation. However, cod distribution has shown wide unexplained fluctuation in the past (e.g. 1977 in Fig. 4), so several years of data from this second period of low abundance are needed to provide a stronger test of the density dependence of temperature selection by cod.
As predicted by models of density-dependent habitat selection (MacCall 1990), the area occupied by cod in the southern Gulf expanded as abundance increased (Swain \& Sinclair 1994). However, the density-dependent changes in cod temperature distribution reported here cannot be attributed simply to range expansion at higher population sizes. Significant negative relationships with abundance persisted for 3 of the 4 measures of cod temperature distribution when analysis was restricted to the geographic range of cod in each year. Because annual variation in the temperature available within the range was statistically controlled in this analysis, these inverse relationships between cod temperature distribution and abundance cannot be merely due to an expansion of range into areas of cold water at high abundance. Instead, as range expanded with increasing population size, cod tended to select relatively cold temperatures from those available within the range. Furthermore, it is clear that the density-dependent changes in distribution of this population include a shift in distribution rather than just an expansion of distribution (Swain \& Wade 1993, Swain 1993a). Bioenergetic considerations (Elliott 1979, Crowder \& Magnuson 1983) predict that temperature preference should be density dependent. The density-dependent changes in temperature distribution observed in this study are in the predicted direction and provide a possible explanation for the shifts in distribution observed for this population.

Density-dependent changes in the spatial pattern of this population have been greater for older cod than for younger cod (Swain \& Wade 1993). We failed to demonstrate significant differences among age classes in the density dependence of temperature distribution. However, for both the index of temperature selection (S) and the median temperature occupied by cod, estimates of the slopes on abundance were steeper for older (Ages 6 to $8^{+}$) than for younger (Ages 3 to 5) cod. In analyses within age classes (not shown here), these slopes were significantly less than zero $(p<0.05)$ for older but not for younger cod after controlling for variation in thermal regime. These results suggest that, like spatial pattern, temperature distribution may be more strongly density-dependent for older cod.

Older cod tended to select colder temperatures than younger cod in the southern Gulf of St. Lawrence in September. This is consistent with results for cod on the eastern Scotian Shelf in summer (Sinclair 1992), but is in contrast to the suggestion that young cod are better adapted to cold temperatures than adults (Templeman \& Fleming 1965, Kao \& Fletcher 1988, Brown et al. 1989). The tendency for older cod to select colder temperatures than younger cod in the wild might reflect differences between age classes in a trade-off between the density-dependent benefits of greater 
food supplies in warm, shallow water and the densityindependent benefits of lower metabolic costs in colder, deeper water (see discussion in Swain 1993a) rather than differences in temperature tolerance. This possibility is consistent with the hypothesis that bathymetric trends in demersal fish size may be linked to temperature and food (Macpherson \& Duarte 1991).

Density-dependent temperature selection has important implications for the productivity of this stock. First, it implies that competition is significant and per capita prey resources are reduced when abundance is high. Second, it involves a shift towards colder temperatures when abundance is high. Colder temperatures and lower prey resources per capita should result in reduced growth rates. Growth rates in this population have declined sharply from the 1970 s when abundance was low to the 1980 s when abundance was high, though other factors such as size-selective fishing may have contributed to this decline in growth (Hanson \& Chouinard 1992a).

Our observation of a negative relationship between cod abundance and temperature distribution provides the first field evidence for the prediction that a decrease in food availability will result in increased use of colder (i.e. less costly) habitats (Elliott 1979, Crowder \& Magnuson 1983). We suggest that prey resources and temperature interact to determine the distribution of cod in the southern Gulf, with cod tending to occupy warm (high-cost) shallow (highresource) areas when abundance is low and cold (lowcost) deeper (low-resource) areas when abundance is high. This hypothesis is consistent with the densitydependent changes in geographic distribution (Swain \& Wade 1993), bathymetric pattern (Swain 1993a) and temperature selection (this study) observed for this population. Laboratory tests for an interaction between food resources and temperature selection have been equivocal. Preferred or mean occupied temperature decreased on reduced rations in most species tested (Javaid \& Anderson 1967, Stuntz \& Magnuson 1976, Reynolds \& Casterlin 1979, Mac 1985, Wildhaber \& Crowder 1990), but decreases were sometimes slight (e.g. $<1.0^{\circ} \mathrm{C}$; Wildhaber \& Crowder 1990) or less than required to maximize growth (Mac 1985). For the bluegill Lepomis macrochirus, results differed among tests. Stuntz \& Magnuson (1976) and Reynolds \& Casterlin (1979) reported declines in preferred temperature on reduced rations, but Wildhaber \& Crowder (1990) found that bluegill strongly preferred $30^{\circ} \mathrm{C}$ (their final preferendum) over $25^{\circ} \mathrm{C}$, even on reduced rations when growth would have been better at $25^{\circ} \mathrm{C}$. Failures to select temperatures that would maximize growth in the laboratory have been attributed to the short duration of laboratory experiments (Stuntz \& Magnuson 1976, Mac 1985, Wildhaber \& Crowder 1990) or to physiological constraints related to acclimation costs (Mac 1985, Wildhaber \& Crowder 1990).

The hypothesis that a decrease in per capita resource availability will result in proportionally greater use of habitats which are less costly in terms of a density-independent factor has been proposed for 3 other habitat combinations. Abrahams \& Dill (1989) developed a model to predict the effects of food availability (the density-dependent resource) and predation risk (assumed to be a density-independent cost) on the distribution of guppies Poecilia reticulata between 2 feeders, one with and the other without a risk of predation. Tyler (1994) developed a similar model to predict the distribution of minnows Rhinichthyes atratulus between 2 sides of a stream tank differing in food supply and current speed. Finally, a similar model was developed by Kramer (unpubl.) to predict the effects of food supply and water depth (associated with a density-independent cost of surfacing to breathe under low oxygen conditions) on the distribution of guppies in a laboratory aquarium. In all 3 studies, changes in the density-independent factor altered habitat selection compared to control tests in which this factor was held constant between habitat patches. The present study suggests that these preliminary efforts at increasing the realism of density-dependent habitat selection models through the incorporation of densityindependent costs may provide useful tools for predicting and interpreting fish distributions on large spatial scales in the natural environment as well as within the confines of small laboratory aquaria.

Acknowledgements. We thank C. J. Foote for suggesting this collaboration, J. Allard, R. Claytor and G. Nielsen for advice on statistics, and A. F. Sinclair, J. M. Hanson, E. M. P. Chadwick, G. A. Chouinard, J. A. Tyler, C. J. Foote and 3 anonymous referees for comments on earlier versions of this paper. Research by D.L.K. is supported by a research grant from the Natural Sciences and Engineering Research Council of Canada.

\section{LITERATURE CITED}

Abrahams, M. D., Dill, L. M. (1989). A determination of the energetic equivalence of the risk of predation. Ecology 70 : 999-1007

Biette, R. M., Geen, G. H. (1980). Growth of underyearling sockeye salmon (Oncorhynchus nerka) under constant and cyclic temperatures in relation to live zooplankton ration size. Can. J. Fish. Aquat. Sci. 37: 203-210

Bigelow, H. B., Schroeder, W. C. (1953). Fishes of the Gulf of Maine. U.S. Fish Bull. Fish Wildl. Serv. 74

Brett, J. R. (1971). Energetic responses of salmon to temperature. A study of some thermal relations in the physiology and freshwater ecology of sockeye salmon (Oncorhynchus nerka). Am. Zool. 11: 99-113

Brett, J. R. (1979). Environmental factors and growth. In: Hoar, W. S., Randall, D. J., Brett, J. R. (eds.) Fish physiology, Vol. VIII. Academic Press, New York, p. 599-675 
Brett, J. R., Shelbourn, J. E., Shoop, C. T. (1969). Growth rate and body composition of fingerling sockeye salmon, Oncorhynchus nerka, in relation to temperature and ration size. J. Fish. Res. Bd Can. 26: 2363-2394

Brown, J. A., Pepin, P., Methven, D. A., Somerton, D. C. (1989). The feeding, growth and behaviour of juvenile cod, Gadus morhua L., in cold environments. J. Fish Biol. 35: $373-380$

Clark, D. S., Green, J. M. (1991). Seasonal variation in temperature preference of juvenile Atlantic cod (Gadus morhua), with evidence supporting an energetic basis for their diel vertical migration. Can. J. Zool. 69: 1302-1307

Clay, D. (1991). Seasonal distribution of demersal fish (Osteichthyes) and skates (Chondrichthyes) in the southeastern Gulf of St. Lawrence. In: Therriault, J.-C. (ed.) The Gulf of St. Lawrence: small ocean or big estuary? Can. Spec. Publ. Fish. Aquat. Sci. 113: 241-259

Crowder, L. B., Magnuson, J. J. (1983). Cost-benefit analysis of temperature and food resource use: a synthesis with examples from the fishes. In: Aspey, W. P., Lustick, S. I. (eds.) Behavioral energetics: the cost of survival in vertebrates. Ohio University Press, Columbus, p. 189-221

Edgington, E. S. (1987). Randomization tests, 2nd edn. Dekker, New York

Elliott, J. M. (1975). The growth rate of brown trout (Salmo trutta L.) fed on reduced rations. J. Anim. Ecol. 44: $823-842$

Elliott, J. M. (1979). Energetics of freshwater teleosts. In: Miller, P. J. (ed.) Fish phenology: anabolic adaptiveness in teleosts. Academic Press, London, p. 29-61

Ferguson, R. G. (1958). The preferred temperature of fish and their midsummer distribution in temperate lakes and streams. J. Fish. Res. Bd Can. 15: 607-624

Fretwell, S. D., Lucas, H. L. Jr (1970). On territorial behaviour and other factors influencing habitat distribution in birds. I. Theoretical development. Acta Biotheor. 19: 16-36

Fry, F. E. J. (1971). The effect of environmental factors on the physiology of fish. In: Hoar, W. S., Randall, D. J. (eds.) Fish physiology, Vol. VI. Academic Press, New York, p. 1-98

Hanson, J. M., Chouinard, G. A. (1992a). Evidence that sizeselective mortality affects growth of Atlantic cod (Gadus morhua L.) in the southern Gulf of St. Lawrence. J. Fish Biol. 41: 31-41

Hanson, J. M., Chouinard, G. A. (1992b). Distribution and feeding of juvenile cod (Gadus morhua) in the principal nursery area of the southern Gulf of St. Lawrence. In: de Lafontaine, Y., Lambert, T., Lilly, G. R., McKone, W. D., Miller, R. J. (eds.) Juvenile stages: the missing link in fisheries research. Can. Tech. Rep. Fish. Aquat. Sci. 1890: 93-103

Hawkins, A. D., Soofiani, N. M., Smith, G. W. (1985). Growth and feeding of juvenile cod (Gadus morhua L.). J. Cons. int. Explor. Mer 42: 11-32

Hurlbut, T., Clay, D. (1990). Protocols for research vessel cruises within the Gulf Region (demersal fish) (1970-1987). Can. Manus. Rep. Fish. Aquat. Sci. No. 2082

Javaid, M. Y., Anderson, J. M. (1967). Influence of starvation on selected temperature of some salmonids. J. Fish. Res. Bd Can. 24: 1515-1519

Jean, Y. (1964). Seasonal distribution of cod (Gadus morhua L.) along the Canadian Atlantic coast in relation to water temperature. J. Fish. Res. Bd Can. 21: 429-460

Jobling, M. (1988). A review of the physiological and nutritional energetics of cod, Gadus morhua L., with particular reference to growth under farmed conditions. Aquaculture 70: 1-19
Kao, M. H., Fletcher, G. L. (1988). Juvenile Atlantic cod (Gadus morhua) can be more freeze resistant than adults. Can. J. Fish. Aquat. Sci. 45: 902-905

Kohler, A. C., Fitzgerald, D. N. (1969). Comparisons of food of cod and haddock in the Gulf of St. Lawrence and on the Nova Scotia banks. J. Fish. Res. Bd Can. 26: 1273-1287

Koutitonsky, V. G., Bugden, G. L. (1991). The physical oceanography of the Gulf of St. Lawrence: a review with emphasis on the synoptic variablity of the motion. In: Therriault, J.-C. (ed.) The Gulf of St. Lawrence: small ocean or big estuary? Can. Spec. Publ. Fish. Aquat. Sci. 113: 57-90

Mac, M. J. (1985). Effects of ration size on preferred temperature of lake charr Salvelinus namaycush. Environ. Biol. Fish. 14: 227-231

MacCall, A. D. (1990). Dynamic geography of marine fish populations. University of Washington Press, Seattle

Macpherson, E., Duarte, C. M. (1991). Bathymetric trends in demersal fish size: is there a general relationship? Mar. Ecol. Prog. Ser. 71: 103-112

Martin, W. R., Jean, Y. (1964). Winter cod tagging off Cape Breton and on onshore Nova Scotia banks. J. Fish. Res. Bd Can. 21: 215-238

Murawski, S. A., Finn, J. T. (1988). Biological bases for mixedspecies fisheries: species co-distribution in relation to environmental and biotic variables. Can. J. Fish. Aquat. Sci. 45: 1720-1735

Nakken, O., Raknes, A. (1987). The distribution and growth of Northeast Arctic cod in relation to bottom temperatures in the Barents Sea, 1978-1984. Fish. Res. 5: 243-252

Perry, R. I., Smith, S. J. (1994). Identifying habitat associations of marine fishes using survey data: an application to the northwest Atlantic. Can. J. Fish. Aquat. Sci. 51: 589-602

Powles, P. M. (1958). Studies of reproduction and feeding of Atlantic cod (Gadus callarias L.) in the southwestern Gulf of St. Lawrence. J. Fish. Res. Bd Can. 15: 1383-1402

Reynolds, W. W., Casterlin, M. E. (1979). Behavioral thermoregulation and the 'final preferendum' paradigm. Am. Zool. 19: 211-224

Rose, G. A., Leggett, W. C. (1988). Atmosphere-ocean coupling and Atlantic cod migrations: effects of wind-forced variations in sea temperatures and currents on nearshore distributions and catch rates of Gadus morhua. Can. J. Fish. Aquat. Sci. 45: 1234-1243

Rose, G. A., Leggett, W. C. (1989). Interactive effects of geophysically-forced sea temperatures and prey abundance on mesoscale coastal distributions of a marine predator, Atlantic cod (Gadus morhua). Can. J. Fish. Aquat. Sci. 46: 1904-1913

Rose, G. A., Leggett, W. C. (1991). Effects of biomass-range interactions on catchability of migratory demersal fish by mobile fisheries: an example of Atlantic cod (Gadus morhua). Can. J. Fish. Aquat. Sci. 48: 843-848

Rudstam, L. G., Magnuson, J. J. (1985). Predicting the vertical distribution of fish populations: analysis of cisco, Coregonus artedii, and yellow perch, Perca flavescens. Can. J. Fish. Aquat. Sci. 42: 1178-1188

SAS Institute (1990). SAS/STAT user's guide, Version 6, Edn 4. SAS Institute Inc., Cary, NC

Scott, J. S. (1982). Depth, temperature and salinity preferences of common fishes of the Scotian Shelf. J. Northw. Atl. Fish. Sci. 3: 29-40

Sinclair, A. (1992). Fish distribution and partial recruitment: the case of eastern Scotian Shelf cod. J. Northw. Atl. Fish. Sci. 13: 15-24.

Smith, S. J., Perry, R. I., Fanning, L. P. (1991). Relationships between water mass characteristics and estimates of fish 
population abundance from trawl surveys. Environ. Monitor. Assess. 17: 227-245

Stuntz, W. E., Magnuson, J. J. (1976). Daily ration, temperature selection, and activity of bluegill. In: Esch, G. W., McFarlane, R. W. (eds.) Thermal ecology II, ERDA Symp. Ser., CONF-750425. Technichal Information Service, Springfield, VA, p. 180-184

Swain, D. P. (1993a). Age- and density-dependent bathymetric pattern of Atlantic cod (Gadus morhua) in the southern Gulf of St. Lawrence. Can. J. Fish. Aquat. Sci. 50: $1255-1264$

Swain, D. P. (1993b). Variation in September near-bottom temperatures in the southern Gulf of St. Lawrence, 1971-1992. DFO Atlant. Fish. Res. Doc. 93/48

Swain, D. P., Sinclair, A. F. (1994). Fish distribution and catchability: what is the appropriate measure of distribution? Can. J. Fish. Aquat. Sci. 51: 1046-1054

Swain, D. P., Wade, E. J. (1993). Density-dependent geographic distribution of Atlantic cod (Gadus morhua) in the southern Gulf of St. Lawrence. Can. J. Fish. Aquat. Sci. 50: 725-733

Templeman, W., Fleming, A. M. (1965). Cod and low temperature in St. Mary's Bay, Newfoundland. Spec. Publ. Int. Comm. NW Atlant. Fish. 6: 131-135

This article was submitted to the editor
Tremblay, M. J., Sinclair, M. (1985). Gulf of St. Lawrence cod: age-specific geographic distributions and environmental occurrences from 1971 to 1981. Can. Tech. Rept Fish. Aquat. Sci. 1387

Tyler, J. A. (1994). Ideal free distributions of stream fish: a model and test with minnows Rhinichthyes atratulus. Ecology (in press)

Waiwood, K. (1981). The predatory impact of cod in the southern Gulf of St. Lawrence - a preliminary account. Comm. Meet. int. Coun. Explor. Sea C.M.-ICES 1981/G:43

Waiwood, K., Majkowski, J. (1984). Food consumption and diet composition of cod, Gadus morhua, inhabiting the southwestern Gulf of St. Lawrence. Environ. Biol. Fish. 11: $63-78$

Wildhaber, M. L., Crowder, L. B. (1990). Testing a bioenergetics-based habitat choice model: bluegill (Lepomis macrochirus) responses to food availability and temperature. Can. J. Fish. Aquat. Sci. 47: 1664-1671

Winters, G. H., Wheeler, J. P. (1985). Interaction between stock area, stock abundance, and catchability coefficient. Can. J. Fish. Aquat. Sci. 42: 989-998

Woiwode, J. G., Adelman, I. R. (1991). Effects of temperature, photoperiod, and ration size on growth of hybrid striped bass $\times$ white bass. Trans. Am. Fish. Soc. 120: 217-229

Manuscript first received: January 12, 1994

Revised version accepted: October 4, 1994 